\title{
A Formação da Literatura Brasileira e o regionalismo
}

\author{
Juliana Santini \\ Universidade Estadual Paulista
}

\begin{abstract}
Resumo: Este trabalho analisa de que modo Antonio Candido cria, em Formação da literatura brasileira, um modelo de interpretação para o regionalismo na prosa literária brasileira que será desenvolvido no conjunto de sua obra e recuperado pela crítica contemporânea.

Pala vras-chave: regionalismo, crítica literária, prosa brasileira
\end{abstract}

\begin{abstract}
papel da produção regionalista na história literária brasileira é analisado por Antonio Candido em grande parte de sua obra. Na verdade, essa problemática encarta-se na interpretação de um movimento dialético entre localismo e cosmopolitismo que fundamenta os estudos do crítico como elemento condicionador das nuances históricas de nossa literatura. Claro está que esse movimento não se distancia da oscilação entre literatura transplantada e afirmação nacional tratada por Candido na Formação da literatura brasileira, entretanto, o que se focaliza nesta reflexão é a maneira peculiar como o crítico insere a problemática do regionalismo nessa dialética e, a partir daí, institui um percurso interpretativo de sua consolidação enquanto instrumento de afirmação nacional, crítica social e investigação da dimensão psicológica do habitante do sertão, o que se desenvolve ao longo do conjunto de sua obra por meio da relação com a ideia
\end{abstract}


de subdesenvolvimento, e se desdobra na crítica contemporânea, que há mais de cinquenta anos faz ecoar o paradigma de análise elaborado pelo crítico.

\section{Regionalismo e subdesenvolvimento}

No volume Literatura e sociedade, Antonio Candido analisa a literatura brasileira do século XX a partir de uma divisão em três etapas, de acordo com a constituição de uma produção que tenta se desvincular dos moldes portugueses. Nesse conjunto, a primeira etapa, circunscrita entre 1900 e 1922, é denominada pelo autor como "Pós-romântica" e qualificada como "literatura de permanência" por promover a conservação das características desenvolvidas pelo Romantismo e o momento que imediatamente o seguiu. Essa idéia de permanência e tudo o que ela representa de atávico e conservador serve de argumento para a interpretação que faz o crítico em relação ao regionalismo que se produziu nos anos que antecederam a Semana de Arte Moderna, em 1922.

A concordar com a interpretação de Literatura e sociedade, o regionalismo literário se consolida, no Brasil, enquanto equilíbrio entre homem e paisagem, somente na década de 30 com o romance do Nordeste, fundindo a tendência neo-realista a uma forma narrativa desprovida dos supostos recalques do princípio do século. Nesse movimento descrito pelo autor, em oposição ao apogeu do romance na terceira década do século XX, o ano de 1945 marcaria uma nova guinada na literatura brasileira, momento em que ocorreria uma separação entre preocupação social e elaboração estética. É essa oscilação entre social e estético que, no limite, poder-se-ia reduzir a tema e forma - que fundamenta a instituição de um percurso histórico e social da literatura brasileira enquanto "literatura de incorporação que vai passando a literatura de depuração". ${ }^{2}$ Entre um e outro extremo, o regionalismo literário impõe-se como uma espécie de termômetro, capaz de resumir em seus traços, ora a aceitação de modelos estrangeiros, ora a tentativa de afirmação - frustrada ou não - de uma representação tipicamente nacional, ou ainda certa autonomia promotora de representações menos artificiais.

A análise contida em Literatura e sociedade retoma e reafirma parte do que fundamenta a interpretação de Antonio Candido em relação à ficção

1. CANDIDO. Literatura e sociedade, p.133.

2. CANDIDO. Literatura e sociedade, p.154; grifos do autor. 
regionalista diante da formação da literatura brasileira no que diz respeito à emancipação de modelos europeus e à edificação da nacionalidade. Ampliando o campo de visão para as malhas de toda a nossa história literária, o regionalismo aparece relacionado ao princípio do romance brasileiro e, situado pelo autor no interior do Romantismo, aos liames da ideologia da independência, que passou a tomar a literatura como instrumento de construção do nacional. Iniciando essa perspectiva, a Formação da literatura brasileira institui uma concepção que atrela o surgimento da literatura regionalista a uma atmosfera de "país novo", inaugurada com a independência da colônia em 1822.

Para que se entenda o conceito de regionalismo desenvolvido nos dois volumes de Formação da literatura brasileira, é necessário que se retorne, portanto, à origem do romance romântico brasileiro e ao significado dessa forma literária em um contexto em que se debatiam a consciência do indivíduo e o senso da história. No bojo do movimento romântico, o romance representaria uma espécie de compensação do individualismo por ter como fundamento de composição a necessidade de ligação à realidade exterior pelo princípio da verossimilhança. ${ }^{3}$ Enquanto forma norteada pela descrição patriótica da realidade, o romance romântico articular-se-ia a essa inclinação pela verossimilhança, de modo a situar sua ação em espaços sociais e geográficos diversos: "Quanto à matéria, o romance brasileiro nasceu regionalista e de costumes; ou melhor, pendeu desde cedo para a descrição dos tipos humanos e formas de vida social nas cidades e nos campos". ${ }^{4}$

A essa observação, duas outras devem ser agregadas para a definição do romance regionalista romântico: em primeiro lugar, seria determinante da natureza da prosa do Romantismo o fato de se constituir a partir da criação de enredo e tipos sem maior elaboração estética ou complexidade temática; em segundo, haveria três graus de distinção na matéria romanesca, determinados pela maneira como se dá a elaboração do espaço no interior da narrativa. Assim, três eixos temáticos desenham-se a partir de ambientação da trama: na cidade (representação da vida urbana), no campo (trabalho com a vida rural), ou na selva (a vida primitiva seria o cerne da ação romanesca). Dessa tripartição decorre uma oposição temática fundamental: de um lado, o indianismo ocupa-se da representação de habitantes primitivos, em fase do isolamento relativamente ao homem urbano;

3. CANDIDO. Formação da literatura brasileira, p. 24. v. 2.

4. CANDIDO. Formação da literatura brasileira, p. 101. v. 2. 
de outro, o regionalismo coloca em cena o habitante rústico, menos isolado da influência urbana e estrangeira por situar-se em um espaço intermediário, ao redor das cidades, porém alheio ao primitivismo total.

Mais do que opor indianismo e regionalismo, Antonio Candido atribui ao segundo importância central no percurso de constituição de uma literatura que, em seu processo histórico, relaciona-se de maneira dialética com a afirmação do nacional e a transplantação cultural. Fundamentais, portanto, são questões que envolvem a já apontada necessidade de verossimilhança de que se revestiu o regionalismo desde sua origem, e, principalmente, certo lastro realista que fomentaria a manifestação de uma pesquisa do país que se iniciou no Romantismo. Não menos importante nesse foco de análise é a presença da figura humana na representação do espaço regional: enquanto criadora de tipos, essa ficção estaria ligada a uma certa dimensão humana, mesmo que incipiente e idealizada, do habitante do interior do país - embora se saiba que essa dimensão liga-se mais à busca de uma fígura-síntese da nação do que à observação do homem a partir de um ponto de vista sociológico mais apurado, o que não era possível para os românticos, dados os liames mantidos pela transplantação cultural.

Essa característica do regionalismo romântico servirá como argumento para que Antonio Candido sublinhe a posição de recusa em relação à literatura produzida no início do século XX. ${ }^{5}$ Sob esse aspecto, embora represente uma extensão da prosa que se originou no Romantismo, a "literatura sertaneja" - com a qual o autor identifica as obras de Afonso Arinos, Coelho Neto e, ainda, Monteiro Lobato - teria encontrado desenvolvimento diverso, de modo a aniquilar o humano em favor do pitoresco e exótico:

É uma verdadeira alienação do homem dentro da literatura, uma reificação da sua substância espiritual, até pô-lo no mesmo pé que as árvores e os cavalos, para deleite estético do homem da cidade. Não é à toa que a "literatura sertaneja", (bem versada apesar de tudo por aqueles mestres), deu lugar à pior subliteratura de que há notícia em nossa história, invadindo a sensibilidade do leitor mediano como praga nefasta, hoje revigorada pelo rádio.

5. CANDIDO. Formação da literatura brasileira, p. 192. v. 2.

6. CANDIDO. Formação da literatura brasileira, p. 192. v. 2. 
No conjunto da estética romântica, o romance teria passado por três fases definidoras no que diz respeito ao tratamento dado a essa relação entre homem e paisagem. A primeira, circunscrita entre 1843 e 1857, desenvolveria apenas rudimentos de análise do homem. A segunda, entre 1857 e 1872, teria no surgimento do indianismo um instrumento para que fosse iniciada a descrição dos costumes regionais em consonância com o princípio de uma consciência em relação à dimensão psicológica do homem. O terceiro momento, iniciado em 1872, veria apurados os recursos e temas das duas fases anteriores, o que se conquistaria com maior objetividade na descrição, análise mais profunda e também objetiva, além de um regionalismo que começava a se organizar em torno de um programa mais coeso.

Na proposta de Franklin Távora ${ }^{8}$ para o desenvolvimento do regionalismo no Norte, fundamentada na pesquisa da terra, no patriotismo regional e na reivindicação de uma posição de destaque para a região, Candido identifica a origem das produções mais características da literatura regionalista brasileira: os ciclos do Nordeste. Essa interpretação sintetiza muito do que significa a natureza do regionalismo na Formação da literatura brasileira: de um lado, um importante fator no processo de autonomia literária brasileira, por partir da necessidade de criação de um tipo regional de que não se tinha um paradigma de representação; de outro, a sustentação de uma tendência realista na prosa literária que se estenderia até a década de 30, encontrando no romance regionalista de então forma e escopo para se consolidar de modo independente das determinações românticas.

A concepção de regionalismo desenvolvida por Antonio Candido na Formação da literatura brasileira é confirmada e renovada no ensaio de título "Literatura e subdesenvolvimento", em que se visualiza a produção regionalista brasileira a partir de um critério que considera dois grandes momentos de definição da nacionalidade. Desse modo, opõem-se: um primeiro momento, o da "consciência de país novo", em que se teria uma "consciência amena de atraso", quando uma visão otimista impulsionava a crença no brasileiro e a consequente idealização de sua imagem como forma compensatória de uma decadência vista apenas como momentânea; e um segundo momento, o da "consciência do subdesenvolvimento", em que a literatura despertaria para uma análise social e humana feita com acuidade, baseada em princípios miméticos que the conferiam verossimilhança e profundidade psicológica.

7. CANDIDO. Formação da literatura brasileira, p. 265-268.

8. TÁVORA. O cabeleira.

9. CANDIDO. Literatura e subdesenvolvimento, p. 158. 
A novidade apresentada pelo ensaio "Literatura e subdesenvolvimento" na análise desse percurso é a localização de um terceiro e derradeiro período, que o autor denominaria "super regionalismo", ${ }^{10}$ produção com outras feições, que supera o elemento local na busca de uma universalidade que parte do regional, porém encontra na investigação da essência humana respaldo para uma prosa que suplanta o social. A universalidade da região não descarta, entretanto, o componente nativista da literatura regionalista que lhe serviu como definição desde seu surgimento; pelo contrário, o que haveria, nesse momento, seria uma assimilação do jogo dialético entre o geral e o particular que marcou toda a nossa história literária.

A sistematização desses três momentos fundamentais do regionalismo em sua constituição histórica é reafirmada no ensaio "A nova narrativa", incluído no mesmo volume de ensaios, quando o autor discute com maior clareza a concepção de "super-regionalismo" a partir de traços da obra de João Guimarães Rosa, definidora por promover a "[...] síntese final das obsessões constitutivas da nossa ficção, até ali dissociadas: a sede do particular como justificativa e como identificação; o desejo do geral como aspiração ao mundo dos valores inteligíveis à comunidade dos homens".

Essa observação acaba por elucidar não apenas a fase inaugurada pelas inovações temáticas e formais introduzidas por Guimarães Rosa, mas também a interpretação do crítico em relação ao regionalismo literário brasileiro: no movimento pendular entre particular e geral, entre a definição de uma literatura e a aceitação dos modelos transplantados, o momento a que corresponde a "consciência amena de atraso" não poderia sustentar uma literatura diferente daquela em que se consolidou o romance romântico como forma de tomada de consciência do país e apropriação literária de temas e espaços nacionais. Sob esse mesmo ponto de vista, a "consciência do subdesenvolvimento" também não originaria outra literatura senão aquela de mergulho na análise local por meio de um engajamento social que tomava homem e meio a partir de uma interpretação sócio-política. Ponto de confluência do local e do mítico, a obra do autor de Grande sertão: veredas sintetiza tese e antítese de modo a mudar, não apenas os rumos da ficção regionalista - o "superregionalismo" que supera o regional -, mas também o paradigma de interpretação crítica do elemento regional na prosa brasileira.

10. CANDIDO. Literatura e subdesenvolvimento, p. 207.

11. CANDIDO. A nova narrativa, p. 208. 
Não menos alicerçada no entrecruzar das noções de região e nação do que outros posicionamentos críticos, ${ }^{12}$ a interpretação de Antonio Candido vai além da mera constatação de uma relação entre o anseio pela nacionalidade e o desenvolvimento de uma literatura que pulveriza o todo nacional em regiões e, ora as toma como porções metonímicas, ora as reconhece enquanto diversidade. Ao atrelar a mudança de trajetória da literatura regionalista brasileira a uma tomada de consciência relativamente ao subdesenvolvimento, o autor traz à tona o vão que se coloca entre a necessidade de definição da nacionalidade e o compromisso com a nação. É claro que mesmo a consolidação de um conceito acerca do que seja nação na história do pensamento brasileiro já é polêmica por si e merecedora de estudos específicos. ${ }^{13}$ Entretanto, é necessário considerar a lacuna apontada entre uma e outra noção, já que um momento em que a ficção regionalista começa a mostrar traços dessa tomada de consciência - no conto pré-modernista de alguns autores - é resumido pelo crítico à simples permanência de moldes românticos.

O fato é que a periodização da ficção regionalista brasileira, esboçada por Antonio Candido em sua obra, acaba por deixar um hiato interpretativo no que diz respeito a alguns autores do princípio do século XX: o conto regionalista pré-modernista merece mais atenção - e a reavaliação do período que emerge de alguns estudos das décadas de 80 e 90 não deixa de comprovar isso -, o que pede uma reflexão acerca do lugar ocupado, não apenas por essa produção no quadro literário nacional, mas também no contexto em que surgiu. Ao reduzi-la sob o epíteto de "literatura caligráfica" - pelo que essa produção apresenta de rebuscado, pitoresco e caricatural -, tal visada crítica ignora o que aí há de inovador, crítico e antecipador de tensões que se desenvolverão com maior proficuidade em outro contexto.

A crítica literária que se constrói sob a inspiração dos estudos de Antonio Candido, de maneira geral, adere ao paradigma de interpretação do crítico,

12. Em 1924, sob o pseudônimo de Tristão de Athayde, Alceu Amoroso Lima propõe uma interpretação da prosa regionalista no volume Afonso Arinos, em que as noções de americanismo, brasileirismo e regionalismo aparecem na base da formação do romance brasileiro. Malgrado a visão de nacionalidade literária que fundamenta a discussão de Amoroso Lima, o papel determinante do subdesenvolvimento e da consciência do atraso na representação estética da região como nação não aparece no paradigma de análise do crítico.

13. A esse respeito, ver CHAUí. Brasil: mito fundador e sociedade autoritária.

14. CANDIDO. Literatura caligráfica, p. 3. 
embora sejam notadas variações justamente quando o assunto tratado refere-se à literatura regionalista do princípio do século XX. A articulação entre literatura e subdesenvolvimento, adotada como ponto de explicação das nuances que definiriam um eixo de transformações determinantes na história da literatura regionalista brasileira, serve sobremaneira ao entendimento do traço característico da produção que marcou o romance em meados da década de 30, embora deixe de iluminar outras arestas do problema. Diante desse quadro, a tomada de consciência em relação ao atraso ou atavismo econômico no Brasil e seus desdobramentos no quadro literário passariam a explicar os dois momentos apontados pelo crítico em seus estudos e serviriam de ponto de reflexão para o que parecia permanecer aquém da sistematização.

\section{O sertão revisitado}

Em texto que propõe uma revisão dos caminhos percorridos pela literatura regionalista brasileira à luz de motivações sócio-econômicas que determinaram diferentes contextos políticos no Brasil, Ligia Chiappini atrela o regionalismo a um posicionamento de aceitação ou recusa das transformações sociais de cada período. O primeiro ponto abordado pela autora é a produção do princípio do século XX, no que diz respeito à relação que estabelece com o movimento modernista e os complexos esquadros desenhados pela industrialização e pelo surto de urbanização e modernização característicos da Belle Époque. Articulando-se a essa diversidade de cores, a ficção regionalista mostra-se como um "movimento compensatório" diante do novo, como se ao processo de modernização do país se opusesse uma literatura que tenta buscar na figura tradicional do habitante interiorano o representante de feições perdidas com o progresso e, principalmente, os traços marginalizados de um homem que se mostra como um contraponto do desenvolvimento.

A autora situa as raízes desse processo no movimento romântico e na reação intelectual de buscar no interior do país a imagem que representasse o sentido da nacionalidade. Embora pareça, em um primeiro momento, tributária do esquema interpretativo que Tristão de Athayde desenvolvera há mais de setenta anos, a leitura de Ligia Chiappini liga-se a liames sociológicos que procuram, na relação

15. CHIAPPINI. Velha praga? Regionalismo literário brasileiro, p. 670 . 
entre dominante e dominado - e na noção de regionalismo compensatório -, uma explicação para a busca do interior como epítome do país. Essa motivação mostrase interessante na sistematização da produção heterogênea do período pré-modernista, em que se teria como base a avaliação de Antonio Candido em relação à trajetória pendular do regionalismo, que serviria tanto como revelação da decadência, quanto como maquiador da realidade por meio da criação de quadros exóticos e pitorescos.

É justamente essa oscilação que se mostra como elemento sustentador do ponto de vista que Ligia Chiappini desenvolve sobre a ficção pré-modernista: na relação entre autor citadino e realidade interiorana a ser desvendada e representada repousariam tonalidades diversas de uma mesma produção. Sob esse aspecto, Valdomiro Silveira, escamoteando a visão do fazendeiro cuja decadência estaria atrelada ao sucesso dos produtores de café no Oeste paulista, encontraria na técnica de composição uma solução para a distância que se colocava entre o homem culto da cidade e a imagem literária que se fazia do sertanejo. ${ }^{16}$

Tem-se, portanto, na interpretação da obra desses dois autores a representação do "ponto de vista do pobre", ${ }^{17}$ a organização de um programa regionalista calcado na exploração dos dados físicos da região, pautado na observação de peculiaridades do ambiente, bem como na pesquisa da fala do caipira. Alheio a generalizações, o estudo da autora traz à tona, na literatura do período, um movimento de oscilação entre a idealização e a caricatura, a realidade e a alienação. Nesse sentido, coloca-se em cena a problemática de uma tomada de consciência que dá seus primeiros passos no conto pré-modernista e na pintura caricaturesca de Monteiro Lobato, que não deixa de caminhar, pari passu, com a retomada de modelos românticos de representação: "fica, pois, ainda com João Simões Lopes Neto e Valdomiro Silveira o mérito (guardadas as diferenças) de buscar uma difícil adequação de estilo ao tema no conto regionalista do chamado pré-modernismo".

16. De 1912, os Contos gauchescos, de João Simões Lopes Neto, são emblemáticos dessa preocupação em anular a distância instituída entre o registro da fala citadina do narrador e a fala interioriana do personagem local. No volume, a voz narrativa é estruturada pela fala do gaúcho campeiro Blau Nunes, de modo que, na coincidência entre personagem e narrador encontra-se a diluição do distanciamento e a instituição de uma voz supostamente mais autêntica.

17. CHIAPPINI. Velha praga? Regionalismo literário brasileiro, p. 690.

18. CHIAPPINI. Velha praga? Regionalismo literário brasileiro, p. 691. 
Essa adequação só se mostraria em sua plenitude na década de 30, com uma produção que se faz em um ponto equidistante entre a visão do dominador, supostamente interessado em mascarar a marginalização provocada pela modernização desenfreada, e o dominado, que tem no ressentimento a base para que se represente a melancolia de um passado perdido. O equilibrio pauta-se na apresentação, sob moldes neo-realistas, de uma realidade enfocada por narrativas preocupadas mais com a denúncia do que com a procura de uma representação estética que não crie um hiato entre forma e conteúdo - como o primeiro grupo modernista se debruçara sobre a forma, era agora possível ocupar-se com o que havia de marginal e desumano no homem do sertão, além de concretizar uma tendência à valorização de tradições esquecidas, traço reivindicado pelo grupo regionalista organizado em torno de Gilberto Freyre desde $1926 .{ }^{19}$

O percurso argumentativo de Chiappini em seu trabalho deixa clara a filiação entre o alicerce de sua interpretação e o modo como se configura a interpretação do regionalismo literário na crítica de Antonio Candido desde a Formação da literatura brasileira até os ensaios de A educação pela noite que, na terceira parte do livro, publicado em 1986 com textos escritos em diferentes ocasiões, atrelam o regionalismo à consciência - ou não - do subdesenvolvimento. Embora a literatura pré-modernista mostre um ponto de discordância entre os autores, Ligia reconhece sua filiação ao pensamento de Candido no momento em que aponta para uma falha na interpretação de parte da crítica literária brasileira, que vê na produção do grupo nordestino da década de 30 o esgotamento da literatura regionalista, de modo que qualquer persistência nesse sentido seria um caso de anacronismo ou falta de criatividade.

$\mathrm{Na}$ verdade, Antonio Candido manifesta sua recusa a esse ponto de vista desde a composição do famoso ensaio "A literatura e a formação do homem", de 1972, em que aponta a literatura regionalista como uma manifestação tributária do subdesenvolvimento, o que invalida qualquer interpretação que a tome como uma categoria superada. Aliada a essa interpretação, Ligia Chiappini aponta para o que nela há de atual, embora não se negue a mostrar o que também há de redutor e unilateral:

A hipótese é de Antonio Candido e poderia resumir-se assim: enquanto houver subdesenvolvimento, haverá novas aparições desse fenômeno literário que manifesta, a seu modo, contradições, ressentimentos e

19. A esse respeito, ver FREYRE. Manifesto regionalista de 1926. 
desigualdades apanhadas de outra forma pelo discurso e pelas lutas políticas. Particularmente me inclino a seguir essa trilha, lembrando apenas que talvez a questão do subdesenvolvimento ainda não seja suficiente para explicar o fenômeno, uma vez que outras assimetrias que não exclusivamente econômicas o determinam interna e externamente nos países subdesenvolvidos [...].

Embora reafirme essa necessidade de reinterpretação dos caminhos trilhados pela literatura regionalista após o ciclo nordestino, a autora deixa aberta a questão, restando menos uma solução do que uma interrogação. O que faz Ligia Chiappini, nesse caso, é lançar um desafio que chama a atenção para a urgência de encontrar um lugar para essa produção literária, começando ainda pelo empreendimento de situar a obra de Guimarães Rosa em relação ao regionalismo literário brasileiro - avaliação que é sugerida por Antonio Candido no momento em que a proposição de um "super regionalismo" ${ }^{21}$ é esclarecida pelo autor em poucas linhas, sem que uma análise mais apurada se constitua.

A possibilidade de permanência do regionalismo na literatura brasileira produzida depois da década de 30 do século XX permanece em suspenso, sem que a crítica literária tenha atado a essa lacuna um fio que preencha ou simplesmente a coloque como incompatível, de modo que parece não haver um consenso - por vezes, nem sequer uma discussão - a respeito do problema, que se torna ainda mais abrangente se forem levadas em consideração obras produzidas posteriormente ao contexto em que se insere Guimarães Rosa, como o trabalho de José Cândido de Carvalho ou, mais recentemente, de autores como Francisco J. C. Dantas, Milton Hatoum e Ronaldo Correia de Brito.

Em artigo de Walnice Nogueira Galvão, essa problemática é silenciada e a autora, ao fazer uma revisão da "importância do regionalismo no Brasil", encerra suas reflexões justamente na análise do romance nordestino da década de 30. Apontando a influência exercida sobre a prosa regionalista brasileira pelo romance americano das duas primeiras décadas do século XX, enquanto "mudança de enfoque do herói individual para o ser coletivo", 22 a autora detém-se no regionalismo de 30, cujo início situa em 1928, com a publicação de A bagaceira, de José Américo

20. CHIAPPINI. Velha praga? Regionalismo literário brasileiro, p. 700.

21. CANDIDO. Literatura e subdesenvolvimento.

22. GALVÃO. Anotações à margem do regionalismo, p. 53. 
de Almeida. Essa ideia de representação de um ser coletivo é interessante na medida em que faz avultar a diluição do esforço de tipificação que - sob diversos matizes, é verdade - define o regionalismo, desde sua origem, como esboço do nacionalismo. O fato é que essa mudança de perspectiva, pouco discutida nesse viés, impulsiona grande parte do que fundou o romance regionalista nordestino, principalmente porque a representação da coletividade tinha a ver, naquele contexto específico, com a tomada de consciência de uma situação de abandono que ia além das agruras naturais implicadas pela seca - escopo do regionalismo naturalista - e se estendia à reflexão acerca da transformação nos processos de produção e da hegemonia econômica do Sudeste em relação a outras regiões do país.

Se, por um lado, esse estado de coisas justifica que a literatura engajada do ciclo nordestino seja apontada como uma forma narrativa que se atém sobremaneira aos conteúdos, reafirmando posições anteriores de que a prosa do período se valeria das conquistas estéticas da geração que o antecedeu, por outro, a objetividade da análise e a crueza dos contornos que desenham o quadro desse romance não permitem que essa produção seja desvinculada dos mesmos moldes naturalistas que cindem a literatura regionalista desde o segundo momento indicado pela autora. Tal conjunto de fatores é visto por Walnice Nogueira Galvão como o desencadeador de um novo paradigma de composição do regionalismo brasileiro a partir da década de 30, de modo que a tendência naturalista serviria de eixo motivador para a avaliação que a crítica faria dessa literatura:

O fato é que essa safra de ficção ao rés-do-chão e aspirando ao documentário jornalístico impôs um cânone que tem seus epígonos até hoje e que dominou a literatura brasileira, impedindo por longo tempo que houvesse percepção estética de autores que não atuassem dentro dessas normas.

E porque coincidiu com a formação de um mercado editorial e de um público leitor, também lança luz sobre a persistência das ramificações do Naturalismo como principal programa estético-literário entre nós. ${ }^{23}$

Essa advertência da autora desdobra-se na medida em que alerta para uma estagnação da crítica literária no que diz respeito à avaliação da produção regionalista após o romance de 30: atentando para a supervalorização dos moldes naturalistas desde então, fica claro que o regionalismo, enquanto categoria estética, estaria fadado ao anacronismo caso não tivesse se emoldurado em formas distintas,

23. GALVÃO. Anotações à margem do regionalismo, p. 55. 
caminhando para além do engajamento e da descrição, como se veria a partir de Guimarães Rosa. Embora atente para o fato, Walnice Nogueira Galvão também não chega a propor uma interpretação do regionalismo após a consolidação do romance nordestino, como se a produção que se sucede a essa fase não pudesse ser enquadrada nos moldes de uma ficção de feições regionais. Como se apontou, esse silêncio por parte dos estudos acerca do regionalismo literário brasileiro cria um abismo entre a sistematização dessa produção e a maneira como ela se constituiu ao longo do século XX.

\section{Local, universal, global: considerações finais}

Essa discussão toma outro rumo a partir da década de 90, quando a problematização em torno da perspectiva regionalista - ou não - de autores contemporâneos impõe que seja revista, não apenas a própria história do regionalismo no Brasil, mas também, e, sobretudo, os diferentes paradigmas de interpretação crítica dessa produção. E é justamente nesse esforço de reinterpretação que se verificam duas vertentes críticas que, contemporaneamente, constituem a exegese do regionalismo no processo de formação e consolidação da literatura brasileira: de um lado, coloca-se a ideia de que o regionalismo teria sido "superado" com a narrativa rosiana, como se o "super regionalismo" identificado por Antonio Candido significasse a sentença de morte da representação do dado local: em favor de uma tonalidade mais humana, mítica e filosófica, pretere-se o olhar mimético, supostamente restritivo e naturalista; de outro, a reiteração de que o regionalismo é uma forma literária tributária do subdesenvolvimento econômico e, por isso, sustenta-se na incorporação estética de regiões em que a globalização não se realizou de modo homogêneo.

Não se pode negar que ambos os direcionamentos críticos partem de orientações interpretativas tomadas de empréstimo à obra de Candido. Ocorre, porém, que a manutenção da filiação entre regionalismo literário e subdesenvolvimento torna evidentes os desdobramentos das observações que compõem o percurso crítico de Candido desde a Formação da literatura brasileira; e, ainda, certo preconceito de parte da crítica contemporânea na aceitação de que a prosa brasileira não se mostra refratária à sobrevivência de peculiaridades simbólicas e culturais de certas regiões afastadas em relação ao eixo Rio-São Paulo. Mais de meio século depois do surgimento das reflexões que se propunham 
determinar os "momentos decisivos" da formação literária no Brasil, Tânia Pellegrini ${ }^{24}$ reafirma dois traços fundamentais à caracterização da dimensão regionalista de parte da prosa literária contemporânea quando compara as escritas de Graciliano Ramos e Milton Hatoum: o compromisso da narrativa regionalista com certo lastro com a realidade e a determinação do subdesenvolvimento na representação de "territórios extremos", marcados por traços distintivos, tanto do ponto de vista sócio-econômico, quanto da perspectiva simbólica, cultural e imaginária de sua configuração.

Considerando que o escopo desta reflexão não diz respeito à pertinência da ideia de regionalismo na prosa contemporânea, mas ao modo como a crítica situa a base de sua argumentação no modelo interpretativo de Antonio Candido, é importante que se considere o posfácio de Davi Arrigucci Jr. à primeira edição do volume de contos Faca, de Ronaldo Correia de Brito. Publicado em 2003, o livro enfeixa narrativas curtas, com linguagem concisa, marcada pela secura de um espaço geográfica e simbolicamente delimitado: o sertão de Inhamuns, no Ceará. Iniciando sua discussão pela narrativa "Lua Cambará", o crítico esclarece os elos que unem a prosa de Ronaldo ao conteúdo da narrativa popular e da saga folclórica, bem como da matéria épica e trágica dos dramas humanos insolúveis, em que merece ênfase a aproximação entre o modo de narrar desses contos e das narrativas rosianas:

De fato, guardadas as devidas proporções, pela matéria e por questões formais, seu [de Ronaldo Correia de Brito] microcosmo ficcional apresenta semelhanças com o universo de Guimarães Rosa e com um filme de Glauber Rocha, "Deus e o diabo na terra do sol", glosado um pouco num super 8 sobre "Lua Cambará".

Em seu todo, o posfácio redunda a ideia da originalidade do autor cearense quando se leva em conta a linguagem sisuda, o ritmo enxuto de uma prosa de raízes populares e filiações míticas. O suposto parentesco com Guimarães Rosa, entretanto, faz retroceder o ponto de vista ao aspecto que aqui se vem frisando: o paradigma de interpretação utilizado por Davi Arrigucci Jr. neste posfácio e em outros ensaios do mesmo livro, tomado de empréstimo ao conjunto da obra

24. PELLEGRINI. Despropósitos, p. 117.

25. ARRIGUCCI Jr. Tempo de espera, p. 137. 
de Antonio Candido, deixa entrever nas suas frestas a concepção de que, nas narrativas de Faca, o dado universal supera o dado local em favor de uma dimensão humana que resgata o lado épico do homem ou a totalidade perdida. Interessante notar, ainda sob essa visada, que no ensaio "Sertão: mar de rios e histórias", o mesmo crítico chama a atenção para a construção da voz narrativa em Grande sertão: veredas, que garantiria a ênfase no registro da fala do sertanejo: "Permite uma reviravolta na prosa ficcional da literatura regionalista, superando-a de vez: ele dá voz ao pobre, ao rústica, cujas palavras eram sempre glosadas na voz do narrador culto da cidade no romance regionalista tradicional [...]". ${ }^{26}$

Publicado em 2007, por ocasião da comemoração dos 50 anos do romance de João Guimarães Rosa, esse ensaio põe à mostra a mesma perspectiva crítica que sustentou "A literatura e a formação do homem", em 1972, e, anteriormente, a argumentação de Antonio Candido acerca da prosa pré-modernista em Formação da literatura brasileira, qual seja, a superação a distância entre a voz do narrador e a fala do sertanejo ou do caipira na prosa regionalista. Tomados isoladamente, os ensaios de Davi Arrigucci Jr. apontam para a importância e a pertinência da interpretação de Candido acerca do regionalismo literário desde a Formação e no conjunto de sua obra crítica - embora o esgotamento do regionalismo com a obra de Guimarães Rosa seja, de fato, a grande incógnita deixada pelo crítico (veja-se que o regionalismo supostamente se esgotaria com Grande sertão: veredas, mas a narrativa de Ronaldo Correia de Brito tem sua dimensão regionalista balizada justamente pelo modelo rosiano de representação).

Inseridos em um espectro mais amplo e ao lado das reflexões de Tânia Pellegrini, Walnice Nogueira Galvão e Ligia Chiappini, os mesmos ensaios confirmam a hipótese de que $A$ formação da literatura brasileira teria legado à obra de Antonio Candido e à crítica contemporânea as diretrizes para interpretação do regionalismo na literatura brasileira, em que se destacam: o processo de formação da história literária brasileira e sua ligação com a representação da identidade nacional; a origem do romance regionalista no Romantismo e seu lastro com o real como necessidade fundadora; a oscilação entre transplantação cultural e afirmação da literatura nacional; o regionalismo literário como tributário do subdesenvolvimento

26. ARRIGUCCI Jr. Sertão: mar e rios de histórias, p. 116. É fato que Arrigucci não deixa de citar a Formação da literatura brasileira em seu texto, mas a ênfase recai sobre as formas do romance brasileiro desde o Romantismo até Grande sertão: veredas, e não na problemática do regionalismo propriamente dita. 
econômico e social do país. Mais de cinquenta anos depois de sua sistematização, o paradigma de análise desenhado por Antonio Candido desdobra-se em sua própria escrita e ecoa em letras outras, impondo as certezas - e também os hiatos e as ambiguidades - como ponto de pauta para a exegese contemporânea, queira ela ou não aceitar a relação orgânica de nossas letras com o subdesenvolvimento.

\section{The Formação da literatura brasileira and the Regionalism}

Abstract: This essay analyses the way by which Antonio Candido creates, in his study Formação da literatura brasileira, a pattern of interpretation to regionalism in Brazilian literary prose that will be developed in his whole work and recuperated by contemporary criticism.

Keywords: regionalism, literary criticism, Brazilian prose

$$
\text { Referências }
$$

ARRIGUCCI Jr. Davi. Sertão: mar e rios de histórias. In: segredos: ensaios. São Paulo: Companhia das Letras, 2010. p. 113-129.

ARRIGUCCI Jr. Davi. Tempo de espera. In: ___ O guardador de segredos: ensaios. São Paulo: Companhia das Letras, 2010. p. 130-137.

ATHAYDE, Tristão de. Afonso Arinos. Rio de Janeiro: Anuário do Brasil; Lisboa: Seara Nova; Porto: Renascença Portuguesa.

CANDIDO, Antonio. A nova narrativa. In: ____. A educação pela noite e outros ensaios. 3. ed. São Paulo: Ática, 2000. p. 199-217.

CANDIDO, Antonio. A literatura e a formação do homem. Ciência e Cultura, São Paulo, v. 24, n. 9, p. 803-809, 1972.

CANDIDO, Antonio. Formação da literatura brasileira: momentos decisivos. 9. ed. Belo Horizonte: Itatiaia, 2000. v.1 e v.2.

CANDIDO, Antonio. Literatura caligráfica. Minas Gerais, Belo Horizonte, ano 9, n. 948, dez. 1984. Suplemento Literário, p. 3-4.

CANDIDO, Antonio. Literatura e sociedade: estudos de teoria e história literária. 2 ed. São Paulo: Companhia Editora Nacional, 1967.

CANDIDO, Antonio. Literatura e subdesenvolvimento. In: A educação pela noite e outros ensaios. 3. ed. São Paulo: Ática, 2000. p. 140-162.

CHAUÍ, Marilena. Brasil: mito fundador e sociedade autoritária. São Paulo: Fundação Perseu Abramo, 2000. 
CHIAPPINI, Ligia. Velha praga? Regionalismo literário brasileiro. In: PIZZARRO, Ana. (Org.). América latina: palavra, literatura e cultura. São Paulo: Memorial; Campinas: Editora da UNICAMP, 1994. p. 665-702. v. 2.

FREYRE, Gilberto. Manifesto regionalista de 1926. Departamento de Imprensa Nacional; Serviço de Educação, 1955.

GALVÃO, Walnice Nogueira. Anotações à margem do regionalismo. Literatura e Sociedade, São Paulo, v. 5, p. 45-55, 2000.

PELLEGRINI, Tânia. Despropósitos: estudos de ficção brasileira contemporânea. São Paulo: Annablume; FAPESP, 2008.

TÁVORA, Franklin. O cabeleira. Rio de Janeiro: Ediouro, 1969. 